\title{
Characteristics of High Performance Organization and Knowledge Productivity of Independent Professionals
}

\author{
Guido Roijen
}

Vesteda Investment Management, The Netherlands

\author{
Jol Stoffers \\ Zuyd University of Applied Sciences, The Netherlands \\ Roland de Vries \\ Human Accompany, The Netherlands
}

\begin{abstract}
High Performance Organization (HPO) characteristics indicate why an organization is able to achieve significantly better results than other organizations and these characteristics can facilitate associations to optimize employees' work outcomes. The independent professional (IP) is an increasingly occurring phenomenon in the labor market that fulfils an organizations' need for flexibility in knowledge productivity. This study focuses on the contribution of HPO characteristics to the knowledge productivity of IP's. It was conducted among managers and HRM professionals in various Dutch knowledge-intensive organizations that frequently enlist the services of IPs. This study found a number of HPO attributes that appeared to contribute to the IPs' knowledge productivity, namely the quality of management, an open and actionfocused organizational culture, and continual improvement and innovation. We will use these results to look ahead and consider the future consequences for professional practice. Managers and HRM professionals should strive to contribute to the incorporation of these characteristics within the organization in order to safeguard and enhance knowledge productivity of independent professionals.
\end{abstract}

Paper Type: Research Paper

Keywords: High Performance Organization, Knowledge Productivity, Independent Professional, Human Resource Management, Organizational Citizenship Behavior 


\section{Introduction}

The labor market certainly is not what it used to be. The economic crisis in recent years has accelerated a number of developments. The outflow of personnel has been severe and is still running in some segments, and new work relationships have taken their place. Under the guise of more efficient business operations and economic interest, flexibility in the labor market has been embraced at an increased pace. Next to that professionals' careers are increasingly heterogeneous: similar competences can be applied and further developed in multiple industries (using transferable skills).

Studies about the changes in the labor market were already published 20 years ago, predicting that one day in the future 'free agents' (Pink, 2001) would emerge. These free agents -- who also referred as independent consultants, self-employed, and freelancers -- represent the rise of knowledge workers. Instead of having a secure job and predictable income, these free agents work independently for oneself (Pink, 2001; Vaiman et al., 2011). We also had an array of expectations from the unknown world of the Internet and its consequences for the economy. In the early 2000s, the share prices and interest rates surged - and subsequently plummeted. The old 'economy' had won. Now, many years later, our economy has a new and very profitable order (Rotmans, 2014). The virtual companies have taken the lead and achieve turnovers and profits that no one would ever have imagined. New insights into market approaches have arisen, we are all networking through the social media - in other words: the world has changed considerably.

In the world of business organization, however, we are still working with bygone assumptions. We refer to employers and employees as if the classic organization, with the classic work contract, is still the only form of employment available. We are aware that the Netherlands has almost 1,000,000 independent professionals (IPs) (Central Bureau of Statistics, 2014), but the literature offers organizations little to no guidelines as to how to effectively deal with a wide diversity of new work relationships.

A recent study by The Netherlands Institute for Social Research (Sociaal Cultureel Planbureau) clearly shows a current swerve with regard to the employers (Van Echteld et al., 2015). A new social dilemma is starting to emerge. Due to the increasing flexibility of labor, employers are reluctant towards contributing to the competence development of IPs. They are no longer prepared to invest in the advancement of staff that will not be around for very long. The paradox is, however, that the flexible staff's share in the employer's total number of workers is increasing.

Professionals and organizations need flexibility - not as a goal in itself, but as a means to secure work and income, whilst maintaining their market and competitive positions (Donnelly, 2008; Fenwick, 2007; Vaiman et al., 2011). Moreover, a growing number of organizations prefer to have a core of staff in fixed employment surrounded by a flexible shell of workers with temporary or project-based contracts. It is expected that the work of organizations will be progressively more project-based and that IPs will play an increasingly important role in flexible shells (Donnelly, 2008).

International Journal of Management and Applied Research, 2017, Vol. 4, No. 2 
The current labor organization has rapidly become a convoluted diffusion of relationships. Our study aspires to help see the consequences of these developments in a different light and contribute to potentially new or alternative interventions at the organizational level. The study was designed to gain insight into the relationship between the characteristics of High Performance Organizations (HPO) (De Waal, 2010) and the knowledge productivity of the IPs in Dutch knowledge-intensive organizations. It was a quantitative study, conducted among managers and HRM professionals in IP-hiring Dutch companies. The results are intended for managers and HRM professionals of organizations, to help them safeguard and enhance the effective deployment of IPs.

\section{The characteristics of HPOs}

Eric Schmidt (2014), CEO of Google, explained it as follows: 'The problem is, most companies today are run to minimize risk, although not to maximize freedom and speed. In other words, most companies are slow by design. They risk killing great ideas and losing talented people. Corporations need an entrepreneurial mind and skill set.' According to Lanting (2014), there are two kinds of companies: the first type is companies that are innovative, proactive and able to go beyond traditional boundaries, whereas the second type is large, inflexible and with a focus on internal processes and less on the customer and market. In the digital age, many organizations can now tap into the collective intelligence which is commonly known as 'crowdsourcing' (Gehl, 2015). Crowdsourcing is an important part of innovation in the new information- and networking society and this makes it possible for (new) organizations to achieve a competitive advantage over the large and inflexible organizations (Aslander and Witteveen, 2010).

The HPO Framework is a theoretical framework that enables an inventory and categorization of the characteristic factors of an HPO. The ones that most frequently appeared in the studies were tested in a worldwide survey among over 3,000 organizations in various industries in order to distinguish the HPOs' most important characteristics. These are the characteristics that form the HPO Framework; it consists of 5 factors, which are briefly described below (De Waal, 2010).

\section{HPO Factor 1: High management quality}

According to De Waal (2010), the first and most important factor is a high quality of management. Managers have, among other things, integrity and are decisive, focused on action and achievements, effective and self-confident. They also have a strong leadership style. They put great emphasis on building relationships of trust with their staff, they coach and facilitate these employers, and they have a strong exemplary role.

\section{HPO Factor 2: Quality of staff}

In the excellent organization, its members are held responsible for their results and they wish to be inspired in order to achieve exceptional ones. That is why the organization trains its members in enhancing their flexibility and resilience.

International Journal of Management and Applied Research, 2017, Vol. 4, No. 2 
HPO Factor 3: Focus on the long term

The third HPO factor is the organization's thinking in the long term. To a HPO, continuity in the long term always goes before profit in the short term. This long-term focus includes all the stakeholders of the organization. The organization creates growth through collaboration with other organizations in the shape of virtual integration of suppliers and customers, and the organization continually seeks opportunities for alliances and collaborative relations (based on a shared vision).

\section{HPO Factor 4: An open and action-focused culture}

In order to come up with new ideas and improve their own performance so as to elevate the organization to a higher level, everyone pays a great deal of time and attention to communication, knowledge exchange, and learning. The managers also welcome and encourage change and improvement by continually striving for renewal.

\section{HPO Factor 5: Continual improvement and renewal}

Continual improvement and renewal, or innovation, are key to the organization. In a HPO, all the staff members feel morally obliged to always strive for the optimal result and get the best out of themselves, their colleagues, and the organization. The organization excels in its core competences and continually renews these - by determining what it is that the organization does best.

\section{The changing nature of work, the rise of the independent professional}

In the early 1990s, Handy (1995) already predicted that, mainly through technological developments and growing competition and partly due to globalization, work would no longer be a place to go to, but an activity that the employee performs. Handy (1995) argued that businesses will revert back to a core of a limited number of staff and bureaucrats.

There are different groups that would offer these core organizations their services, namely the low skilled workers (an unschooled and 'replaceable' group of employees) and the middle and high skilled workers (a group of knowledge workers). However, as Autor (2010) points out, the labor market has enlarged its demand for high-skilled (high-wage) workers and low-skilled (low-wage) workers, while opportunities for middle-skilled (middle-wage) jobs have declined (job polarization). In line with this IPs are marginal represented within the entrepreneurial middle class (Goffee and Scase, 2015). The deployment of IPs varies. In many companies of a service providing nature, IPs are deployed for interim jobs and specialist activities. These often are the activities that require knowledge that is not immediately available within the organizations themselves.

The job profile that has been put together in order to arrive at a full-time package of duties will no longer be the leading component, but rather the contribution that the knowledge worker can make to the core of the company. This is a development that was also aptly described by Daniel Pink (2001) in The Free Agent Nation.

Furthermore, in the Dutch labor market - also in the traditional sectors of healthcare, education, and logistics (truck drivers) - we see that the new legislation aimed

International Journal of Management and Applied Research, 2017, Vol. 4, No. 2 
specifically at the flexibility of labor has led to a rapid shifting of duties to flexible or contingent workers (Vaiman et al., 2011), who may also be hired in case of staff shortages (Lenssen and Manuel, 2014) or in a time when a project is poorly conceived (Fenwick, 2007).

The involvement of the 'traditional' staff is reflected in, among other things, the psychological contract. The psychological contract originally stems from the employer-employee relationship. Still, the 'new' psychological contract does hold elements that also apply to an IP. Gasperz and Ott (1998), for instance, identified a number of beliefs about employees, such as responsibility for their own employability and loyalty to their own career as well as independency vis-à-vis the employer, all of which can also be said of an IP.

A relational contract holds a social exchange relationship, whereas a transactional contract implies economic exchange. Trust and involvement, for example, are part of a relational contract, while monetary exchange is an aspect of its transactional counterpart (Torka, 2003). According to Rousseau (1995), it is the HRM policy that determines the presence, or absence, of a relational psychological contract, in which the formal contract is of secondary importance. The longer or more often a client hires an IP, the more likely the existence of a relational psychological contract and the more unlikely the chance of merely a transactional contract, due to the social elements involved.

Smith et al. first introduced the term Organizational Citizenship Behavior (OCB) in 1983. According to Organ (1988, p.4), 'organizational citizenship behaviour(s) $(O C B)$ are behaviour( $s)$ of a discretionary nature that are not part of employees' formal (role) requirements, but nevertheless promote the effective functioning of the organization'. Blatt (2008) researched the OCB of temporary knowledge workers. Her conclusion was that these temporary knowledge workers do not have as close a bond with the organization itself as the employees that hold an employment contract. However, when it comes to practice, temporary knowledge workers do show this OCB (involvement) in their collaboration with internal 'colleagues' and their external networks. Her study suggests that temporary knowledge workers attach great value to operational collaboration and positive relationships with colleagues and external contacts - even though the traditional themes of social exchange, organizational identification, and impressing the management do not play a prominent role in their temporary work. This detached relationship is emphasized by Van Echteld et al. (2015), which found that employers do not invest in the competence development of flexible workers.

Blatt (2008) concludes that these findings imply that temporary knowledge workers distinguish themselves from regular employees (and other types of temporary workers), especially when it comes to their perceptions and motives. As Fenwick (2007) puts it, these independent knowledge workers always resist control while staying connected with direct 'colleagues' and the external network, and they always working 'in-between'. In other words, the effects of OCB are visible, but it is prompted by other motives when compared to the 'traditional employees'.

International Journal of Management and Applied Research, 2017, Vol. 4, No. 2 
A knowledge worker has an extensive knowledge base, which they use for the benefit of the company by working towards the improvement and innovation of products, services, and processes (Fenwick, 2007). They are able to develop new knowledge through continuous learning and applying it in their work environment. This new knowledge can subsequently be used to improve and innovate with the current and future clients.

\section{Knowledge productivity}

According to Weggeman (2004), knowledge productivity can be best defined as the degree to which knowledge can be effectively and efficiently deployed to perform a certain operational or mental task in order to achieve a specific goal.

Peter Drucker (1999) identified a number of factors that influence knowledge work productivity (Stam, et al., 2004), such as continual renewal of a knowledge worker's own responsibility, the knowledge work requires continual learning and education (interaction), the quality is at least as important as quantity - with the quality standard depending on the definition of the task, and, finally, the knowledge worker must be cherished in order to grow. Next to that it is not their knowledge itself but rather the productivity of the knowledge worker that will eventually determine an organization's success (Harrison and Kessels, 2004; Stam, et al., 2004).

Individual work performance (IWP) is a term that is frequently used in organizations where the management is primarily interested in how to make an employee as productive as possible. Companies tend to focus on it, because it is one of the core indicators for team and organizational achievements; it can contribute to the productivity and the competitive advantage of the organization. The ability to establish, monitor, and, when necessary, intervene in IWP has gained growing importance, especially in terms of an employee's long-term employability. It was for this purpose that the IWPQ (Individual Work Performance Questionnaire) was developed. It is an unequivocal instrument to establish individual work performance (Koopmans, 2012). It includes the following factors: first, task performance which refers to behavior that directly or indirectly contributes to the technical core of the organization' (Borman and Motowidlo, 1993); second, contextual performance which refers to behavior that supports the organizational, social and psychological environment where the technical core tasks are performed (Borman and Motowidlo, 1993), and lastly, counterproductive behavior which refers to behavior that harms the well-being of the organization (Rotundo and Sackett, 2002).

In our study, we explored the following question: 'Which organizational characteristics, according to the HPO Framework (De Waal, 2010), contribute to the knowledge productivity of IPs according to the IWPQ (Koopmans, 2012)?'

This question was investigated through the 5 following hypotheses:

Hypothesis 1: The quality of management contributes positively to the knowledge productivity of IPs.

Hypothesis 2: A high degree of responsibility for results among an organization's employees has a positive effect on the knowledge productivity of IPs.

International Journal of Management and Applied Research, 2017, Vol. 4, No. 2 
Hypothesis 3: A long-term focus has a positive impact on the knowledge productivity of IPs.

Hypothesis 4: An open and action-focused organizational culture contributes to the knowledge productivity of IPs.

Hypothesis 5: Continual improvement and innovation within an organization contributes positively to the knowledge productivity of IPs.

\section{Methodology}

The study was conducted among managers and HRM professionals at higher occupational levels who use their own networks to hire IPs. We used a convenience sample. Convenience sampling involves drawing samples that are both easily accessible and willing to participate in a study (Teddlie, 2007). The research approach in this study was deductive. It was an explorative study, since it was a method to look into the effect of the HPOs' specific characteristics on the effectiveness of IPs. It focused on acquiring new insight (Saunders, et al., 2011). The most appropriate strategy for this deductive study was a questionnaire, for reasons of feasibility - both in time and financially (Saunders, et al., 2011). The questionnaire as a method, Saunders (2011) argued, allows more control over the research process and provides data that can easily be compared after standardization. We used a cross-sectional research approach; the data collection provided a snapshot, in which we examined which of the HPO characteristics contribute to the knowledge productivity of IPs.

We ensured a wide research population in a variety of organizations. The measurements were, as much as possible, performed in the same period of 4 weeks; the outcomes were anonymized (of which the respondents were informed beforehand). We worked with the validated questionnaires of High Performance Organizations (De Waal, 2012b) and the Individual Work Performance Questionnaire (Koopmans et al., 2013). For all analyses, $p$-value $=<0.05$ was assessed as significant (Saunders, et al., 2011).

The HPO questionnaire was based on the research by De Waal (2010) and the questionnaire that he used in various studies. De Waal's validated questionnaire used a 10-point scale, where 1 represents the minimum value (requires major improvement), and 10 the maximum value (excellent), which we also adopted.

All HPO factors demonstrated good internal consistencies, with Cronbach's alpha coefficients ranging from .78 to .94 . In the processing of the data, the scores were added up and averaged, which rendered one score per HPO factor. The questionnaire measured as to how the respondents believed their organization scored on each HPO factor, after which we hypothesize to link these scores to the knowledge productivity of IPs.

We also used the IWPQ, a questionnaire that comprised the factors task performance, contextual performance, and counterproductive performance (Koopmans, et al., 2013). This questionnaire enabled us to map out the knowledge productivity of IPs as perceived by managers and HRM professionals. The IWPQ was developed for

International Journal of Management and Applied Research, 2017, Vol. 4, No. 2 
research purposes as a short questionnaire that helps assess IWP among a generic population of employees. The subscale for task performance includes 5 items, the subscale for contextual performance measures over 8 , and the one for counterproductive work performance over 5. Per item, the respondent must choose from the answers 'rarely', 'sometimes', 'regularly', 'frequently' and 'always'. The score per item may vary from 1 to 5 (Likert scale), where 1 point is awarded for the score 'never' and 5 points are attached to 'often'.

\section{Results and conclusions}

The sample consisted of 81 respondents (managers and HRM professionals) working at higher occupational levels within 38 Dutch knowledge-intensive organizations operating in different industries. Sampling criteria included the geographical representation of the companies, their various branches, and regularly hiring IPs. Companies were approached via the researchers' personal contacts in association with the Research Centre of Employability (convenient sampling), 57\% of these respondents were managers. The outcomes showed that the greater part of the respondents enlisted IPs for a minimum of 3 months; 34 respondents hired them for more than 6 months. More than 25\% of the clients commissioned IPs for 32 to 40 hours; at 13\%, 0 to 8 hours that was the least selected option.

The literature indicates that an organization may refer to itself as a HPO if it has an average HPO score of at least 8.5 (De Waal, 2012a), Our research revealed that 77 of the 81 respondents did not regard their own organization to be a HPO; merely 4 respondents did.

As for the results, these will be discussed below for each hypothesis separately.

Hypothesis 1: The quality of the management contributes positively to the knowledge productivity of IPs.

Table 1: Correlation between management quality (HPO characteristic) and the knowledge productivity of IPs (IWPQ factors)

\begin{tabular}{ll}
\hline & Management quality... \\
\hline$\ldots$ in relation with task performance & $r_{s}=0.19$ \\
$\ldots$ in relation with contextual performance & $r_{s}=0.25^{*}$ \\
$\ldots$ in relation with counterproductive performance & $r_{s}=-0.24^{*}$ \\
\hline$* p<0.05$. &
\end{tabular}

Table 1 presents the Spearman's Rho correlation between the quality of management and the performance of IPs. The table shows that a higher quality of management has a significant correlation with a higher contextual performance and a significant decline in counterproductive behavior. No significant relationship was found between management quality and the task performance of IPs. Therefore this hypothesis was partly supported.

A possible explanation for the non-significant correlation between management quality and task performance, is that IPs intrinsically adopt certain behavior in their work. This might have the consequence that the influence of management quality is

International Journal of Management and Applied Research, 2017, Vol. 4, No. 2 
less important to their performance than the regular staff's. As an explanation for the significant correlation between management quality and the contextual performance of IPs, Blatt (2008) suggested (in line with OCB) that the operational collaboration and positive relationships with colleagues and external contacts (the context) play a prominent role.

Hypothesis 2: A high degree of responsibility for results among an organization's employees has a positive effect on the knowledge productivity of IPs.

Table 2: Correlation between employees' responsibility (HPO characteristic) and the knowledge productivity of IPs (IWPQ factors)

\begin{tabular}{ll}
\hline & Responsibility of employees... \\
\hline$\ldots$ in relation with task performance & $r_{s}=0.18$ \\
$\ldots$ in relation with contextual performance & $r_{s}=0.29^{*}$ \\
$\ldots$ in relation with counterproductive performance & $r_{s}=0.10$ \\
\hline$* p<0.05$
\end{tabular}
$* p<0.05$.

Table 2 shows a positive significant correlation between a staff members' result responsibility and their contextual performance. No significant correlation between staff members' result responsibility and the task performance or counterproductive work behavior of IPs was found. The hypothesis was, therefore, partly rejected.

The absence of a significant association between the staff's result responsibility and the task performance of IPs might also be explained from the intrinsic motivation with which IPs perform their work. Result responsibility is assumed to have no effect on it. The non-existence of a significant correlation between staff's result responsibility and counterproductive work behavior may be explained by the great number of socially desirable answers that were given (median 1.4 on a 5-point scale for the answers 'rarely' or 'sometimes'), The IPs' perceptions and motives at work might also be an explanation for the non-significant correlation with counterproductive work behavior (Blatt, 2008).

Hypothesis 3: A long-term focus has a positive impact on the knowledge productivity of IPs.

Table 3: Correlation between long-term focus (HPO characteristic) and the knowledge productivity of IPs (IWPQ factors)

\begin{tabular}{ll}
\hline$\ldots$ in relation with task performance & Long-term focus... \\
$\ldots$ in relation with contextual performance & $r=0.23^{*}$ \\
$\ldots$ in relation with counterproductive performance & $r=0.21$ \\
\hline$* p<0.05$ & $r_{s}=-0.05$ \\
\hline
\end{tabular}
$* p<0.05$.

A greater degree of long-term focus leads to a significantly higher task performance. No significant correlation between long-term focus and the contextual performance or counterproductive work behavior of IPs was found. This hypothesis was, therefore, partly rejected. The lack of a significant correlation between the focus on the long term and the contextual performance of IPs might be explained by the diversity and external focus in the statements that determined the long-term focus in the HPO questionnaire (De Waal, 2012b).

International Journal of Management and Applied Research, 2017, Vol. 4, No. 2 
A possible explanation for the non-existence of a significant association between the long-term focus and IPs' counterproductive work behavior might be produced from the degree to which socially desirable answers were given to the questions relating to the latter (median 1.4 on a 5-point scale for the answers 'rarely' and 'sometimes').

Hypothesis 4: An open and action-focused organizational culture contributes to the knowledge productivity of IPs.

Table 4: Correlation between an open and action-focused organizational culture (HPO characteristic) and the knowledge productivity of IPs (IWPQ factors)

\begin{tabular}{ll}
\hline & $\begin{array}{l}\text { Open and action-focused } \\
\text { chananizational culture... }\end{array}$ \\
\hline$\ldots$ in relation with task performance & $r=0.23^{*}$ \\
$\ldots$ in relation with contextual performance & $r=0.32^{*}$ \\
$\ldots$ in relation with counterproductive performance & $r_{s}=-0.11$ \\
\hline$* p<0.05$ &
\end{tabular}

$* p<0.05$

An open and action-focused culture correlates positively with higher tasks as well as contextual performance. No significant relationship was found between an open and action-focused culture and IPs' counterproductive behavior. Due to this absence, the hypothesis was partly supported.

The higher proportion of socially desirable answers given to the questions about IPs' counterproductive behavior (median 1.4 on a 5-point scale for the answers 'never' or 'rarely') might explain why we did not find a significant correlation. Another possible explanation might be provided by the research by Ruth Blatt into OCB among IPs (Blatt, 2008), since it may be deduced from the literature that a positive OCB leads to a decrease in counterproductive work behavior. Spector and Fox (Spector and Fox, 2002), for instance, posit that the negative behavior that can be observed in counterproductive work performance is actually opposite to the positive behavior visible in OCB. They also argue that both types of behavior have many similar causes. Both are voluntary reactions to situations occurring in organizations, with emotional attached. OCB is enhanced by positive emotions, whereas counterproductive work behavior is boosted by negative emotions (Spector and Fox, 2002).

Hypothesis 5: Continual improvement and innovation within an organization contributes positively to the knowledge productivity of IPs.

Table 5: Correlation between continual improvement (HPO characteristic) and innovation and the knowledge productivity of IPs (IWPQ factors)

.. in relation with task performance $\quad r=0.25$

$\ldots$ in relation with contextual performance $\quad r=0.48^{*}$

$\ldots$ in relation with counterproductive performance $\quad r_{s}=-0.01$

$* p<0.05$

There is a significantly positive correlation between a higher degree of continual improvement and innovation, and task and contextual performance. No significant relationship was found between continuous improvement and IPs' counterproductive

International Journal of Management and Applied Research, 2017, Vol. 4, No. 2 
behavior. Due to this absence, the hypothesis was also partly supported.

A possible cause for the lack of a significant association might lie in the minimal dispersion of the scores on the subscale for counterproductive behavior. As above, the degree of socially desirable answers given to the questions here might be a possible explanation.

Through an investigation of a number of hypotheses, this study aspired to provide an answer to the following question: 'Which organizational characteristics, according to the HPO Framework (Handy, 1995), contribute to the knowledge productivity of IPs according to the IWPQ (Koopmans, 2012)?'

Although not significant for all the HPO factors, it was found that the HPO factors of quality of management, an open and action-focused culture and continual improvement and innovation particularly correlate with, or contribute to, the knowledge productivity of IPs. A key issue here is that primarily the relational and communicative side of management, the 'soft skills', are of paramount importance. Here, OCB and the psychological contract create a bond between IPs, management and colleagues.

\section{Practical implications}

In new economic work relationships where control runs merely via an economic assignment, the factor of influence on professionals' productivity will have to be facilitated in another way. In our research, we saw that immaterial factors such as the quality of management, an open and action-focused organizational culture, and continual improvement and innovation are important if the knowledge productivity is to be increased - even if there is no formal work relationship. These factors revolve around trust.

The conclusions from the study discussed here, which looked into the factors that can have a positive impact on IPs' knowledge productivity, strongly support the assumption that their open, innovative, risk-taking, entrepreneurial behaviours (Fenwick, 2007; Ireland et al., 2003) is of key importance to the organizations that successfully operate with a view to the future. This should not be propagated by their management in a single word, but also be reflected in actual deeds and roles. As for IPs, entrepreneurial behavior (Rauch and Hulsink, 2015) is an essential element of their professional stock-in-trade if they are to be an appreciated and productive partner in new economic (work) relationships. Managers and HRM professionals should strive to contribute to the incorporation of these characteristics within the organization in order to safeguard and enhance knowledge productivity of independent professionals.

We now have to accept that the new work relationships have a different balance. In the past, the employer-employee relationship in our social-democratic society was by definition lopsided, at the disadvantage of the employee; in other words: the employer had a greater duty of care. By their advocating for flexibility in the labor market, the employers have widened the gap and increased their distance from the employee. This

International Journal of Management and Applied Research, 2017, Vol. 4, No. 2 
has resulted in a relationship that is, in fact, a partnership between two independent parties: the employer versus the IP. This distance will only continue to grow from now on, especially in sectors that will predictably be faced with a scarcity of knowledge. As with other strategic alliances, the success factors of the partnership cannot do without thorough consideration, and the results of this study indicate that the social factor will be increasingly determinant. Improvement in productivity can, therefore, only be achieved by active dedication to immaterial factors. It requires integrative leadership as well as collaboration to spiral opposed interests to a new optimum (Trompenaers, 1997).

\section{Limitations and Future Research Recommendations}

As is the case with any research study, there are always limitations. The sample used was largely based upon convenient sampling strategy; herewith external validity might be limited. Furthermore, this study did explore the clients' (managers and HRM professionals) perceptions of the IPs' performance, and not the IPs' self-perception of their knowledge productivity. Follow-up research involving IPs self-perception is therefore recommended. Moreover, our study was cross-sectional; that is, data were collected at one point in time, and causality cannot be determined. Future research using longitudinal methods might be used in order to address issues of causality (Taris and Kompier, 2003), and reciprocal relationships (Wright et al., 2005), Moreover, a cross-validation of branches (labour and product/service markets) and (national) cultures is encouraged.

\section{References}

1. Aslander, M. and Witteveen, E. (2010), Easycratie: De toekomst van werken en organiseren [Easycratie: The future of work and organization]. Den Haag: Sdu Uitgevers bv.

2. Autor, D. H. (2010), The polarization of job opportunities in the U.S. labor market. Washington, DC: Center for American Progress and The Hamilton Project.

3. Blatt, R. (2008), "Organizational citizenship behavior of temporary knowledge employees”, Organization Studies, Vol. 29, No. 6, pp. 849-866.

https://doi.org/10.1177/0170840608088704

4. Borman, W. and Motowidlo, S. (1993), "Expanding the criterion domain to include elements of contextual performance". In Schmitt, N. and Borman, W. (ed.), Personnel Selection in Organizations, San Francisco: Jossey Bass. pp. 71-98

5. Central Bureau of Statistics (CBS) (2014), ZZP'ers: Een groep met vele gezichten [Self-employed without employees: A group of many faces]. [Online] Available from: https://www.cbs.nl/nl-nl/nieuws/2014/51/zzp-ers-een-groep-met-velegezichten [Accessed on 3 Feb 2017].

6. De Waal, A. (2010), The characteristics of a high performance organisation.

International Journal of Management and Applied Research, 2017, Vol. 4, No. 2 
Hilversum: Center for Organizational Performance.

7. De Waal, A. (2012a), De toegevoegde waarde van het 'High Performance'Organisatie Raamwerk [Added value of the High Performance Organisation Framework]. Holland / Belgium Management Review, Vol. 16, No. 4, pp. 50-52.

8. De Waal, A. (2012b), "Characteristics of High Performance Organizations", Journal of Management Research, Vol. 8, No. 3, pp. 39-71. https://doi.org/10.1108/17515630710684178

9. Donnelly, R. (2008), "Careers and temporal flexibility in the new economy: an Anglo-Dutch comparison of the organisation of consultancy work", Human Resource Management Journal, Vol. 18, No. 3, pp. 197-215. https://doi.org/10.1111/j.1748-8583.2008.00072.x

10. Drucker, P. (1999), "Knowledge worker productivity: The biggest challenge", California Management Review, Vol. 41, No. 2, pp. 79-94. https://doi.org/10.2307/41165987

11. Fenwick, T. (2007), "Knowledge workers in the in - between: network identities", Journal of Organizational Change Management, Vol. 20, No. 4, pp.509 - 524. https://doi.org/10.1108/09534810710760054

12. Gasperz, J. and Ott, M. (1998), Management van Employability, nieuwe kansen in arbeidsrelaties [Management of employability, new opportunities in labour relationships]. Assen: van Gorcum.

13. Gehl, R. W. (2015), "Sharing, knowledge management and big data: A partial genealogy of the data scientist", European Journal of Cultural Studies, Vol. 18, No. 4-5, pp. 413-428. https://doi.org/10.1177/1367549415577385

14. Goffee, R. and Scase, R. (2015), The Entrepreneurial Middle Class (Routledge Revivals), Routledge.

15. Handy, C. (1995), Beyond Certainty: The changing world of organisations. Londen: Hutchinson.

16. Harrison, R. and Kessels, J. W. M. (2004), Human Resource Development in a Knowledge Economy: An Organisational View. New York: Palgrave Macmillan.

17. Ireland, R. D., Hitt, M. A., and Sirmon, D. G. (2003), "A Model of Strategic Entrepreneurship: The Construct and Its Dimensions", Journal of Management, Vol. 29, No. 6, pp. 963-989. https://doi.org/10.1016/S0149-2063_03_00086-2

18. Koopmans, L. (2012), Voorlopige handleiding IWPV [Provisional manual IWPQ]. Amsterdam: Body@Work TNO Innovation for Life - VU medisch centrum.

International Journal of Management and Applied Research, 2017, Vol. 4, No. 2 
19. Koopmans, L., Bernaards, C., Hildebrandt, V., Van Buuren, S., Van der Beek, A., and De Vet, H. (2013), "Development of an Individual Work Performance Questionnaire", International Journal of Productivity and Performance Management, Vol. 61, No. 1, pp. 6-28. https://doi.org/10.1108/17410401311285273

20. Lanting, M. (2014), Olietankers en speedboten: Wendbaar werken in de 21ste eeuw [Oiltankers and speedbotes: Working manoeuvrable in the $21^{\text {st }}$ century]. Amsterdam: Uitgeverij Business Contact.

21. Lenssen, R. and Manuel, K. (2014), Dansend naar de toekomst [Dancing towards the future]. Leidschendam: Publisher Quist.

22. Organ, D. W. (1988), Organizational citizenship behavior: The good soldier syndrome. Lexington MA: Lexington Books.

23. Pink, D. H. (2001), Free agent nation: How Americans new independent workers are transforming the way we live, New York: Warner Books.

24. Rauch, A. and Hulsink, W. (2015), "Putting entrepreneurship education where the intention to act lies: An investigation into the impact of entrepreneurship education on entrepreneurial behavior", Academy of Management Learning and Education, Vol. 14, No. 2, pp. 187-204. https://doi.org/10.5465/amle.2012.0293

25. Rotmans, J. (2014), Verandering van tijdperk: Nederland kantelt [Change of era: The Netherlands shift]. Boxtel: Aeneas.

26. Rotundo, M. and Sackett, P. (2002), "The relative importance of task, citizenship, and counterproductive performance to global ratings of performance: a policycapturing approach", Journal of Applied Psychology, Vol. 87, No. 1, pp. 66-80. https://doi.org/10.1037/0021-9010.87.1.66

27. Rousseau, D. (1995), Psychological contracts in organizations: Understanding written and un-written agreements. Newbury Park, CA: Sage Publications.

28. Saunders, M., Lewis, P., Thornhill, A., Booij, M., and Verckens, J. (2011), Methoden en technieken van onderzoek [Methods and techniques of research]. Amsterdam: Pearson Benelux.

29. Schmidt, E. and Eagle, A. (2014), How Google works. New York: Grand Central Publishing.

30. Smith, A., Organ D. W., and Near J. (1983), "Organizational citizenship behavior: Its nature and antecedents", Journal of Applied Psychology, Vol. 68, No. 4, pp. 653-663. https://doi.org/10.1111/j.1744-6570.2006.00043_9.x

31. Spector, P. and Fox, S. (2002), “An emotion-centered model of voluntary work behavior: Some parallels between counterproductive work behavior and 
organizational citizenship behavior", Human Resource Management Review, Vol. 12, No. 2, pp. 269-292. https://doi.org/10.1016/S1053-4822(02)00049-9

32. Stam, C., Weggeman, M., Lekanne Deprez, F., Andriessen, D., Kessels, J., and Verdonschot, S. (2004), Kennisproductiviteit. Het effect van investeren in mensen, kennis en leren [Knowledge productivity: The effect of investment in people, knowledge and learning]. Amsterdam: Pearson Education Benelux.

33. Taris, T. W., and Kompier, M. (2003), "Challenges in longitudinal designs in occupational health psychology", Scandinavian Journal of Work, Environment and Health, Vol. 29, No. 1, pp. 1-4. https://doi.org/10.5271/sjweh.697

34. Teddlie, C. and Yu, F. (2007), "Mixed methods sampling: A typology with examples", Journal of Mixed Methods Research, Vol. 1, No. 1, pp. 77-100. https://doi.org/10.1177/2345678906292430

35. Torka, N. (2003), Flexibel maar toch betrokken [Flexible but still involved]. Enschede: Twente University Press.

36. Trompenaers, F. and Hampden - Turner, C. (1997), Riding the waves of culture: Understanding cultural diversity in business, $2^{\text {nd }}$ edition. London: Nicholas Brealey Publishing.

37. Van Echteld, P., Schellingerhout, R., and Voogd-Harmelink, M., van (2015), Vraag naar arbeid [Demand for labour]. Den Haag: Sociaal Cultureel Planbureau.

38. Wright, P. M., Gardner, T. M., Moynihan, L. M., and Allen, M. R. (2005), "The relationship between HR practices and firm performance: Examining causal order", Personnel Psychology, Vol. 58, No. 2, pp. 409-446. https://doi.org/10.1111/j.1744-6570.2005.00487.x

39. Vaiman, V.; Lemmergaard, J. and Azevedo, A. (2011), "Contingent workers: needs, personality characteristics, and work motivation", Team Performance Management: An International Journal, Vol. 17, No. 5/6, pp. 311 - 324. https://doi.org/ 10.1108/13527591111159036 